\title{
Framing the Argument to Broaden Kenya's Limited Fiscal Space for Health Financing by Introducing Zakat
}

\author{
Laila Abdul Latif* \\ Doctoral Researcher at Cardiff Law School, University of Nairobi, Kenya
}

Received: June 11, 2018; Published: June 20, 2018

*Corresponding author: Laila Abdul Latif, Doctoral Researcher at Cardiff Law School, University of Nairobi, Kenya, Email: latif@uonbi.ac.ke

\begin{abstract}
Finance is, as it were, the stomach of the country, from which all other organs take their tone. One such organ is the public healthcare sector. Healthcare financing in Kenya continues to remain underfunded. The problem of limited finances is not new, it flows out of Kenya's colonial past and government's arguments are clothed in clichés: the budget is not sufficient to meet all financing needs for the country and so, health spending must be limited. At independence, Kenya targeted growth as the primary driver of development and relegated spending on healthcare until growth was stabilised. This political ideology framed as African Socialism that explains directing finances towards economic growth at the expense of healthcare financing has resulted in a health sector that is unevenly distributed to favour urban areas at the expense of the poor rural and suffers from a dearth of essential medicines, and unavailable dispensaries and health centres at local community levels. The health budget since 2010 has also been regressing with government placing reliance on user fees and out of pocket payments for health needs to be covered. The current revenue streams are incapable of generating additional taxes without burdening the poor. At the global level there are calls for alternative health financing strategies. This paper responds to that call by identifying a potential revenue base for the Kenyan government: zakat.
\end{abstract}

Keywords: Budget; Colonisation; Domestic Resource Mobilisation; Fiscal Law; Health Financing; Islamic Law; Kenya; Zakat

\section{Introduction}

I begin this paper by arguing that the budget defines the Kenyan state and society's fiscal relationship. This relationship in turn influences the availability and accessibility of social services whose provision is affected by either an increase or decrease in the budget. Among the social services that the Kenyan government bears a legal duty to provide is healthcare. The health budget, however, has been on a regressive scale since 2010 [1]. As at 2018, the government has allocated $4 \%$ to the health budget compared to $7.1 \%$ in 2010 . I argue that under funding the health sector is rooted in Kenya's history. Sir Alfred Milner in 1923 referred to public health as the then colonial government's Cinderella to reflect the financial constraints that impeded delivery of healthcare in Kenya [2]. Its continued reduction has further restricted the growth of the health sector evenly throughout the country following independence in 1963. Public health in rural Kenya is fragile. The lack of healthcare workers, functioning equipment, essential medicines and proximate health facilities within the poor rural areas raises two questions. First, whether there is a need to increase domestic spending on public health. Second, whether an increase in public health spending will result in improving access and availability of public health.
In answering these questions, I begin by considering the existing structure of the health sector and current health programs to understand the impact finance has played in their development. In doing this, I trace the development of the health sector from Kenya's colonial past to its current devolved political and governance structure. Next, I examine the commitment of government in financing the health sector and discuss the adequacy of government's health budget allocation. I then address the twin issues of whether there really is a need to increase health financing or a need to improve financial governance. This is important to establish the problem that the paper seeks to inquire into. Finally, I conclude by making observations on the current innovative methods that supplement the limited health budget. The paper provides a background understanding of the Kenyan public health sector. It restricts its discussion to health financing in order to establish whether there is a need to consider looking for revenue resources from elsewhere in order to supplement the health budget.

\section{Background on the Kenyan Health Sector}

In 1920 when Kenya became a British colony, the colonial government established a political structure for its governance. Gov- 
ernance under this structure was hierarchical and centralised. At the apex was the British government represented by the governor. The region was divided into 8 provinces each governed by a provincial commissioner. The provinces were further divided into districts headed by a district commissioner. Districts were also divided into locations and sub-locations where district officers and chiefs were appointed to maintain law and order [3]. This political structure to some extent enabled the delivery of healthcare services. At the location and sub-location levels, the rural population accessed healthcare through dispensaries. At the district level, health centres were established. Provincial hospitals were found in some of the provinces and the national level had the referral hospital. This health structure developed during the colonial period from 1895 when Kenya was first declared a protectorate to 1963 when Kenya declared independence. At independence, the health structure was retained and its problems also inherited. In order to appreciate the context of these problems, I begin by discussing the organisation of the health system as it developed during British colonisation. I then trace the development of the colonial health system as it moulded after independence and as it exists presently in 2018.

\section{The Colonial Period}

The provision of healthcare for the Africans was not among the objectives of Britain in colonising East Africa. Her objective was trade [4]. The health objective resulted out of the need to contain and prevent the spread of plague and other tropical diseases endemic to East Africa, which were encountered frequently from 1889 to 1963 . At home, Britain had invested money in scientific research in order to gather information on tropical diseases, their prevention and cure. Thus, western medicine and sanitation measures played a key role in preventing the spread of disease in Kenya [3]. The Public Health Ordinance of 1913 was enacted in order to implement sanitation measures. It was assumed by the colonial government that the poor and unhygienic conditions of the Indian markets and African living quarters in the major towns would adversely impact the health of the European settlers. Therefore, the Ordinance required the segregation into separate zones of Europeans, Indians and Africans in the major towns [3]. Outside the major towns, the colonial government relied on the missionaries to provide healthcare services. This meant that in providing healthcare the colonial government discriminated in favour of the urban areas where the European settlers resided and in the towns where trade was conducted $[5,6]$.

Concomitant to the provision of healthcare a number of problems emerged for the colonial government. Greater concentration in urban areas of hospitals meant that the rural areas lacked adequate doctors, nurses, medical assistants and dressers in dispensaries and health centres. Because the Africans were not trained as healthcare providers, the health workforce was imported from Britain and India [6]. A further problem of limited finances resulted in the colonial government restricting the provision of healthcare to preventive measures within the major towns with sanitation as its top priority. Thus, at the start of World War 1, when the Africans were being selected for recruitment as porters and carrier corps, medical examination revealed that the majority of them were in poor health. Further, after the war the African's demand for healthcare increased against a health system that was still in its infancy. This resulted in the following changes to the colonial health system. Firstly, Africans were trained as doctors, nurses, medical assistants and dressers. Secondly, mission health facilities were subsidised so that the rural areas would have greater access to and availability of healthcare services. Thirdly, a health policy was developed to further strengthen the healthcare system, and lastly, a health financing strategy was adopted in order to increase the fiscal space for generating health revenue. The latter led to the establishment of the Local Natives Councils that I discuss next.

To implement the changes to the colonial health system, funding was required. The primary aim of the colonial government still focused on trade and not towards increasing finances for the delivery of healthcare services in the colony. The emergence of political tensions in Kenya after World War 1 that also identified lack of access to healthcare as a growing concern for the Africans resulted in the fiscal decentralisation of healthcare. The Local Natives Ordinance of 1924 was enacted to empower the Local Natives Council; constituted of the area chief and tribal elders, to raise revenue locally for specific development projects, such as schools, dispensaries and health centres. The colonial government remained responsible for the referral hospitals, medical training of Africans, purchasing essential medicines, and remuneration of the healthcare workforce. Despite this the rural areas under the Local Native Councils constantly faced shortages of medicines, equipment and healthcare workers. This led to Chief Koinange of Kiambu and the Kavirondo Taxpayers Welfare Association that had been formed in 1924 by Chief Ezekiel Apindi; who represented the African welfare, to demand that the colonial government account for how much of the budget was directed towards African needs. Their argument centred on the discrepancy between increased levying of local rates in addition to the hut and poll taxes, and the provision of social services such as health [5]. This is the first reference to fiscal responsibility of the government to society seen to be expressed in the budget for social services.

The empowerment of Local Native Councils to levy rates locally led to a healthcare system that was unevenly distributed. Health infrastructure developed within the resource rich local native areas while the poor rural areas continued to lack basic access to healthcare. In reaching these areas, the government relied on missionaries to provide healthcare services before establishing government run health facilities. However, the Mau Mau uprising in 1952; being comprised of Kikuyu youth challenging the legitimacy of the colonial government and demanding political autonomy shifted the focus of the colonial government to address political representation of the Indians, Arabs and Africans within the colonial government [5]. This later led to independence. The health sector between 1950 and 1963 was prioritised after the concerns with political representation, economic development, land, and education were met. By this time the Local Natives Councils had been abolished. The local chiefs no longer had the fiscal autonomy to raise local revenues. 
In concluding this section, I want to mention three sources that have dealt more fully with the present subject. The works of Ndege, Beck, and Iliffe. George Ndege in his book has criticised the colonial government for developing a fragmented healthcare system in Kenya skewed to favour urban development where the European settlers resided, and ignoring the rural areas where majority of the Africans lived. On the contrary, Beck and Illife have discussed the positive role played by the colonial government in introducing western medicine and medical training in Kenya, while also outlining the difficulties experienced. They have described the governance structure for health that was established without which it would not have been possible for the colonial government to provide access to healthcare at the local levels. Repeating these authors discussions here adds nothing original. Their work however, has pointed me to further examine the implications of the lack of a health financing strategy towards the overall development of the healthcare sector. Having drawn on their accounts, I now argue that the colonial healthcare structure that was retained at independence without a financing strategy resulted in wider fiscal implications that stagnated the further growth of the health sector.

\section{Independence}

The Independence Constitution altered the political structure that was in place during colonial rule in Kenya. The newly independent state was to adopt majimboism, which meant political and fiscal autonomy of regions from the central government, in other words devolution. However, a year after independence the Constitution was amended in favour of a centralised government. The colonial political structure was remodelled with the central government now at the apex of the hierarchy delegating certain powers and functions to the provincial commissioners who further delegated functions to the district commissioners. The latter then required district officers and area chiefs to implement orders at their locational and sub-locational levels. An in-depth discussion on the changing nature of Kenyan politics entrenching centralisation after independence has been discussed by Okoth Ogendo, and Ghai and McAuslan [7]. I draw on their accounts to discuss the emerging political landscape in Kenya following independence. My contribution, however, is to extend their narrative to examine the effect the political regimes had on the development of the health sector and its financing between 1963 and 2002 [7] and include my independent analysis after 2002 to present day Kenya.

For the next 39 years following independence in 1963, the Kenya African National Union (KANU) remained in control of government. In 1965, the KANU government prepared Sessional Paper No. 10 on African Socialism and its Application to Planning in Kenya [7]. This Paper summarised KANU's political ideology and guided government policy. The Paper outlined the framework for economic development and social progress for the newly independent nation. Okoth Ogendo renounced this ideology as a mere political tool coined by the first President Jomo Kenyatta in order to advance his policy on the centralisation of the State and to promote a cohesive spirit of nationalism in light of the calls for secession that followed independence [7]. I hold a different view. African socialism is a political and economic system that is based upon the African tradition of mutual social responsibility. This means that the State accepts to take upon itself the responsibilities for social services and recognises the reciprocal response of society's contribution as a group and as individual members. This reciprocal response automatically results through the payment of taxes, which are then redistributed by the State towards the provision of social services.

The Sessional Paper however, focused more on growth than on the provision of social services. Growth was seen as a driver of economic development and social progress. It was to take priority over the provision of social services. Under African Socialism, healthcare was a social service that the government was obliged to provide to all its citizens. The Paper recognised the limitation of financial resources in providing free healthcare to all citizens. Healthcare was not seen as a driver of growth, but dependent on economic development. The Paper thus justified the provision of limited medical services for the destitute at dispensaries and health centres while recommending the development of the National Hospital Insurance Fund (NHIF) as the basis of Kenya's future expansion of free healthcare services. Consequently, African Socialism failed to attach fiscal responsibility on the part of government for healthcare. The availability of resources thus directed the development of the health sector and operationalization of various health policies and programs to which I now turn.

The provision of healthcare services in Kenya was guided first by the Sessional Paper No. 10 of 1965 that required immediate steps to be taken towards family planning education in order to control the growing rate of population that was deemed undesirable for growth. However, the 1966-1970 Development Plan that operationalized the policy on health in the Paper instead sought to address the problem of regional imbalances in access to healthcare and the lack of an adequate health workforce. An increase in the number of public hospitals and aid to mission hospitals was also planned alongside the control of malaria and tuberculosis. This Plan continued under the 1970-1974 and the 1974-1978 Development Plans that also included the provision of family planning and maternal healthcare [7]. By 1978 the government shifted its focus towards immunization, nutrition, sanitation and health education under its Kenya Expanded Program on Immunization that was prepared to operationalize achieving the World Health Organisation's goal of 'Health for All by the year 2020'. I argue that the objectives under these Plans and the Program depended on the availability of funds to be operationalized. However, neither the Plans nor the Program specified a comprehensive health financing strategy to achieve their objectives.

In 1982 the District Focus Rural Development Plan was prepared by the KANU government. It sought to decentralize the provision of social services at community level and empowered the district officers to raise local revenue to finance community development projects. This Plan, however, was politically motivated. Its aim was to curb the growing political dissent that arose out of regional imbalances and concentration of political power in the ruling Kalenjin ethnic group. The Plan, therefore decentralized the provision of social services by granting limited fiscal autonomy to the district officers. This power was abolished in 1994 when Kenya 
prepared its first health policy $[8,9]$. This policy was to be implemented in two time bound stages; through the National Health Sector Strategic Plans I and II to be implemented from 1994 to 2004 and 2005 to 2010 respectively. The policy consolidated the objectives under the previous Plans and Program with the aim of providing a comprehensive public healthcare package. Missing in the 1994 health policy was the financing framework under which the NHSSP I would operate. In operationalizing the NHSSP II the government recognised the importance of private firms, households, donors including faith based organisations, and health insurance schemes as potential revenue sources without going further to explain how these revenue sources would be targeted.

The 1994 health policy reflecting the government's commitment to providing healthcare fell short of identifying the financing framework that would implement the policy's objectives. The government continued to lag behind in addressing regional imbalances in accessing healthcare, lack of adequate healthcare workers, limited supply of essential medicines, and unavailable healthcare facilities at community level. In 2010, government aimed to reverse these trends by devolving healthcare. Health devolution is the most recent political strategy devised by the government to provide equitable healthcare regionally. This strategy provides Kenya's 47 counties with the autonomy to raise revenue locally. Following devolution, the government prepared the Kenya Health Policy 2012-2030 [10] to be implemented under the Kenya Health Sector Strategic and Investment Plan 2014-2018 [10]. The current policy has identified 12 health programs that sum up the entire public health needs of the country without a corresponding health financing strategy [10]. It is estimated by a separate study that the implementation of these programs will cost the national government Kenya Shillings 1,103 trillion. The study also estimated that the government shall experience a shortfall of Kenya Shillings 242 billion [10]. Health policies that are not financially planned continue to increase the gap between the rural and urban access to healthcare.

This section has identified the policies and plans through which the Kenyan government has sought to provide healthcare. I have limited my discussion to the content of the plans, program and the policies prepared by the government in addressing the health needs of the Kenyan population without extensively discussing the methods used to finance the health needs. I have also pointed out that an overall comprehensive strategy for financing these policies and plans has been lacking. Consequently, the question that arises is how then has the government financed healthcare? I answer this next.

\section{The Health Financing Framework}

My argument under this section is that the absence of a fiscal health framework has resulted in limited access and availability of healthcare services in Kenya. Yet, despite this framework, the government has prepared various health policies and plans through which healthcare is delivered countrywide. The delivery of the health programs under these policies and plans would not have been possible without their financing. The absence of a fiscal health framework therefore, has not stalled the healthcare sector. The public health sector continues to function and provide basic services. Government continues to supply essential medicines to the hospitals, health centres and dispensaries. Healthcare workers are also trained and remunerated. However, limited financing continues to reverse the progress made. The frequent strikes by doctors and nurses over low wages, poor infrastructure, outdated equipment and stock out of medical supplies are some of the problems restricting the development of the healthcare sector. I argue that a fiscal health framework would solve some of these problems and sustain the healthcare sector in the long term.

There is a difference between a fiscal health framework and a health financing framework. The former is the source of earmarked revenues targeted for health spending. The latter draws from the fiscal health framework of what is available so that specific sums can be appropriated for financing specific health needs. Fiscal law is the body of law that governs the availability and use of public funds. I describe the term fiscal health law to mean such public revenue that is earmarked specifically for healthcare. For example, $2 \%$ out of the $16 \%$ imposed as value added tax in Kenya that could be earmarked for healthcare. In planning a health financing framework, government would therefore look into the fiscal health fund to allocate additional funds for financing healthcare. A fiscal health fund would therefore serve to work alongside the health budget. These are two frameworks currently missing from healthcare policy, plans, programs and discourse in Kenya.

Instead healthcare financing depends on a percentage of the national budget that is allocated to the health sector and additional financial support is provided through donor aid. Budget financing is dependent on domestic and international mobilization of revenue sources, both of which are limited. I now address each of the two sources separately beginning with the domestic sources. These revenue sources are raised through taxes, licensing fees, rates, levies, duties and service charges. Grants and borrowings by the government from foreign states and international bodies such as the World Bank feature as international revenue sources. These also include donor aid. It is not clear from the budget prepared by Kenya's Ministry of Finance what sources of domestic resource mobilisation are earmarked for healthcare. There are no formal rules that govern the percentage of the budget to be apportioned for health and from what sources at the national and county level. The health budget is entirely dependent on the availability of funds which are tied to prioritised health needs as set out under the prevailing policy.

As such health financing through the budget remains minimal and constrained. Between the fiscal years 2013-14 and 2014-15 after devolution, $3.8 \%$ of the total budget was allocated to the national health sector. This budget was increased to $4.1 \%$ in the fiscal years 2015-16 and 2016-17, but in 2017-18, it was reduced to $3.9 \%$. This echoes the government's position under Sessional Paper No. 10 of 1965 that favoured growth over increase in health spending. I must point out at this stage that following devolution, each county is responsible to set aside its health budget from the total revenue allocated to it by the national government. Under the Fourth Schedule to the 2010 Constitution counties are responsible 
for the promotion of primary healthcare, ambulance services and county health facilities. Whereas the national government remains responsible for the development of the health policy and maintaining the national referral health facilities to which the allocated budget referred above is applied. Country governments are responsible to prepare their own health financing strategies.

Article 209 (3) (c) of the 2010 Constitution provides counties with the fiscal autonomy to impose taxation - "A county may impose any other tax that it is authorised to impose by an Act of Parliament". This article creates the fiscal space to either increase available domestic revenue sources or impose new domestic taxes. The article does not specify for what purposes a tax can be imposed; it merely provides counties with the discretion to impose a tax. I argue that this creates the enabling environment for the making of a fiscal health framework. However, specific legislation is required to justify linking article 209 (3) (c) to the making of a fiscal health framework. No county has utilised this article in imposing taxes earmarked for healthcare that would have provided some direction on the implication of my argument. Further, the most recent Kenya Health Policy 2014-2030 is also silent on a health financing strategy. There is no legal framework that provides for revenue mobilisation specific for healthcare. Health financing therefore, remains dependent on the budget with no reference to an independent fiscal health framework.

A contrary argument may be advanced upon a review of the Health Act, No. 21 of 2017 challenging my position on the lack of a fiscal health framework. The objective of section 86 (1) of the Act is to lead towards the preparation of a health financing framework. Such a framework is to ensure financial access to universal health coverage through targeted measures. The first measure concerns developing mechanisms for an integrated national health insurance system and its regulation. The second measure requires a cost sharing mechanism between the national and individual county governments to be agreed upon. The third measure considers defining a framework for public financing of healthcare, and the last measure relates to identifying a standard health package to be financed through prepayment mechanisms. I find that these measures are mere guidelines in giving legislative effect to article 43 (1) (a) of the 2010 Constitution that provides - "Every person has the right to the highest attainable standard of health, which includes the right to healthcare services, including reproductive healthcare". Under article 21 (2) it is clear that the State is to "take legislative, policy and other measures, including the setting of standards, to achieve the progressive realisation of the rights guaranteed under article 43". I will next address each of these measures before revisiting my argument.

In response to the first measure, a similar form of a national health insurance system currently exists in the country. This is the National Hospital Insurance Fund. The fund provides health coverage to formal sector employees with an option for informal sector workers to also subscribe to the benefits of the fund. In providing healthcare coverage, the fund is dependent on the financial contributions made by both employers, employees and the government.
The fund managers have no powers to mobilise additional revenue sources save from the returns on their investment of contributions not immediately required. The primary source of revenue for the fund are the contributions made. A fiscal health framework identifies different revenue streams for healthcare and collectively governs the use of the available revenue for specific needs. Contributions from the fund would perhaps be directed towards the purchase of essential medical equipment for health centres while also paying for medical costs, while a percentage of total income tax would ensure training and deployment of healthcare workers at community level and adequate supply of medication.

The proposal for a cost sharing mechanism between the national and county governments under the Health Act is a political measure. Such an agreement would only arise after a health program has been identified and budgeted. It is in meeting the deficit in the county budget that this measure would be appropriate. Cost sharing further implies that revenue sources would have already been identified with which the national government would agree to meet the county governments deficit. Cost sharing therefore, is a secondary health financing strategy. It depends on the availability of revenue sources. A fiscal health framework identifies different streams of revenue sources in addition to those already available and earmarks them for healthcare.

The third measure requires defining a framework for public financing of healthcare. I find this terminology ambiguous. It is not clear what is meant by the term to define a framework for public financing of healthcare. Rather than attempting to expound on the meaning contemplated by the legislature in the use of the term defining, I would argue that the measure does not expressly state the need for an operational health financing framework. I will explain this. An operational health financing framework identifies the health programs that require financing and costs them. It then refers to the fiscal health framework to identify what revenue streams have been earmarked for healthcare before drawing on them to finance the selected health program. In defining a framework for public healthcare financing, the government is seeking to conceptualise the meaning of a financing framework. Perhaps this is an important first step towards formulating a fiscal health framework.

The last measure contemplated as a health financing strategy relates to identifying a standard health package to be financed through prepayment mechanisms. My response to this measure is that it would only work if two reciprocating conditions were met. First, the health package should have been identified and costed. Second, revenue sources must have been earmarked in advance and set aside following the costing. Without these two conditions being met, the standard health package would meet the same fate as the previous health programs that could not be fully implemented due to insufficient funds. A fiscal health framework would act as an umbrella strategy through which healthcare is planned, costed and delivered. Each health program would then have its specific financing scheme that would be guided under the fiscal health framework. Further, the fiscal framework would act as the oversight scheme through which healthcare is made accessible and available to all. 
Having considered the implications of the four measures and the fact that they have not been implemented since the Act was enacted in 2017, I reiterate my argument. Health financing remains dependent on the budget with no reference to an independent fiscal health framework. I now turn to address the extent of government financing of healthcare and whether there is a need to increase domestic spending on health.

\section{The Glaring Gap in Health Financing}

This paper then asks whether Islamic fiscal law can support health financing in Kenya. My approach in answering this question lies in establishing a link between Islamic law, human rights, and fiscal sociology. Under Islamic law, there is consensus among the four main schools of legal thought under the Sunni creed on revenue mobilisation. Common among these revenue sources is the zakat, that I translate to mean a wealth tax annually imposed on savings and assets. Zakat is domestically available in every country having a Muslim population that meets the eligibility criteria for paying the tax. Zakat revenue is religiously prescribed to be targeted towards specific beneficiaries in financing their wellbeing. I question its potential as a health financing strategy by attempting to place zakat within the parameters of human rights law. My argument is that in applying human rights law to introduce Islamic law for financing healthcare shall redefine the current state - society's fiscal relationship. This in turn, I assume, shall lead to a new fiscal sociology for the Kenyan health sector [11-18].

Under human rights law the concepts of progressive realisation and maximum available resources are core towards achieving the rights set out under the International Covenant on Economic, Social and Cultural Rights. The concept of progressive realisation recognises the difficulty of resource constraints and that there are legitimate reasons why a state may not be able to fully realise the right to health. Progressive realisation therefore, means that a country must take planned and targeted steps towards full realisation, but is not to be criticised for not immediately achieving the highest standard of health for its people if that is not attainable. The concept of maximum available resources on the other hand, requires states to individually mobilise to the maximum the revenue that is domestically available to finance economic, social and cultural rights. I isolate for critical examination the concept of maximum available resources to assess the potential of broadening the concept to include Islamic revenue sources. I contend that linking zakat to maximum available resources shall give legitimacy to a state that seeks to widen its revenue base to tap into religious funds. Such legitimacy would redefine the state - society fiscal relationship.

Fiscal sociology was advanced by Schumpeter in 1918. In his theory, Schumpeter claimed that the state and society relationship is defined by taxation. That public finances shaped the structure of society. Adolf Wagner in 1890 came close to linking taxation to the structure of a society when he claimed that the level of economic development was linked to a country's revenue generating abilities. He connected economic development to public finance but did not extend his theory to the structure of the society that enabled the generation of such revenue. Schumpeter made the connection in
1918 and Weber Stanislavsky in 1986 supported this connection. This paper draws on Schumpeter's theory. I also argue that the state and society relationship is defined by taxation which in turn is expressed through the budget. My approach towards the application of Schumpeter's theory, however, is different. First, I apply his theory to the Kenyan health sector, and second to Islamic taxation. I briefly discuss this next.

Schumpeter did not restrict the understanding of the state-society relationship to a specific category. The provision of social services such as healthcare I would argue reflects this relationship. The state's obligation in providing healthcare and the extent of its availability for society's use falls within Schumpeter's theoretical framework. The more the budget allocated for healthcare the better its access and availability. In the previous section, I pointed out the percentage of the budget that had been allocated for healthcare between 2013 and 2018 and argued that the limited budget resulted in health inequities regionally. This follows that the limited health budget has shaped the state and society's relationship in terms of access to available healthcare. The state can only provide healthcare based on the revenue sources that are available. Society can only access the extent to which the revenue sources make it possible for healthcare to be delivered.

Schumpeter took a conventional approach to taxation that is tax imposed on income, profits, goods and services. I seek to broaden the fiscal understanding of what constitutes taxation. In doing so, I ask whether religious taxes or revenue sources can fit within a broader understanding of taxation. The impact of introducing a different understanding of taxation could redefine the state and society relationship on healthcare. The significance of this aim can only become apparent after addressing two issues. One, whether there exists a health financing gap that justifies the need to increase domestic spending on public health, and two, if there is a need to look for sources outside existing revenue streams for health. I now respond to these issues.

The health budget for financing its recurrent and development expenditure for the $2017 / 18$ fiscal year was set by the government at $3.9 \%$. Its sufficiency can be tested by examining whether the current health budget meets the government's domestic and international obligations for health financing. In the previous section, I established that there is no legislative requirement or a financing strategy setting a minimum percentage for health financing. There is no fiscal health framework that directs neither revenue mobilisation for health nor a set target for annual health spending. This means that no domestic obligation on setting a minimum percentage towards financing health yet exists. Under African Socialism government's position was quite clear. Revenue resources are to be spent towards growth. Spending on social services while the targets for economic development were not met was considered undesirable. This ideology prevailed for over three decades under the KANU regime after independence until a new government was formed under a different political party led by Mwai Kibaki; the third president. Even under Kibaki and later Uhuru Kenyatta the trend of a limited health budget continues. Even the current gov- 
ernment's position on healthcare reflects African Socialism. Article 43 (1) (a) of the 2010 Constitution on the right to health may shift this position.

The Kenyan government made specific commitments towards health financing at the regional and international levels. These commitments have not yet translated into law. They remain aspirations. At the regional level, Kenya in 2001 under the Abuja Declaration agreed to allocate $15 \%$ of its total budget to health. The need to increase health financing was further reiterated in the Addis Ababa Declaration of 2006 on community health in the African region, the 2008 Ouagadougou Declaration on Primary Health Care and Health Systems in Africa and in the 2012 Tunis Declaration on Value for Money, Sustainability and Accountability in the Health Sector. At the international level, the World Health Organisation recommends governments to commit $5 \%$ of their total budget to health if governments are to achieve a target of $90 \%$ coverage of for maternal and child health services. Kenya is yet to implement this recommendation and meet the $15 \%$ Abuja health target.

The 2016/17 fiscal year statistics show that the government had budgeted $4.1 \%$ for health but its spending on health had pushed the budget to $19.16 \%$. This additional financing was met through external borrowings, donor aid, and out of pocket payments by individuals at the point of accessing healthcare. These statistics reveal that a larger percentage of health financing in 2016/17 was through public debt, donor aid and the imposition of user fees. Further, health spending for the 2015/16 fiscal year cost the government $18.97 \%$ of its total budget compared to the $4.1 \%$ allocated for health. These recent statistics demonstrate that health financing in the long run is not sustainable. The current revenue streams are not sufficient to support Kenya's overall budget. Increased borrowings to finance the budget create a growing debt that impacts negatively on development. The imposition of user fees at public health facilities only prevents the poor from accessing healthcare. These statistics justify the need to look for additional funds outside the existing revenue streams for health.

The potential of government to source for additional domestic revenue sources depends on the economic conditions of its population. $49 \%$ of the urban population and $53 \%$ of the rural population in Kenya live below the poverty line [19]. Since they do not earn an adequate income, they are not taxed. This limits the tax revenue that the government is able to then collect from its population. Instead, formal sector employees earning taxable salaries shoulder the burden of taxation. The taxable profits declared by private corporations also provide government with a revenue source. Not all private corporations are transparent with their profit declarations and operate various tax avoidance schemes that result in loss of revenue for the government. In sourcing for additional funds, an increase in taxation would only increase the burden on the working class and dissuade the private sector from investing domestically. Generating additional domestic revenue targeted for healthcare would then have to be from elsewhere. Before I advance zakat as a potential source for additional revenue, I will first explain what more funds for health would accomplish.
There must be specific health objectives for which additional domestic revenue can be used to finance. In the previous paragraphs, I established that the Kenyan budget in the 2016/17 fiscal year was financed through public debt. Sourcing for additional revenue domestically for health would therefore play an important role in leading the health sector towards self sustainability. In 2007, $38 \%$ of sick Kenyans did not access healthcare because they lacked money [20]. Data from the World Bank showed that in 2010 there were 1.4 hospital beds per 1000 people [21], 0.868 nurses and midwives per 1,000 people, and 0.199 physicians per 1,000 persons in 2013 [21]. Maternal deaths as at 2015 stood at 8,000 per year. On regional distribution of health facilities, the rift valley region maintained the highest number, followed by the eastern region. The north eastern region continued to have the lowest concentration of health facilities out of the 10,506 public health facilities operated by the government countrywide [25]. As at October 2015, these facilities lacked drugs, healthcare workers, and medical equipment [22]. Additional domestic revenue sources for health would aim to reduce these disparities.

The government has identified health devolution as a strategy to increase access to healthcare at community level. Devolution may have the potential to provide a solution for sourcing additional domestic revenue for health at county level. I argue that a fiscal health framework would guide counties towards this solution. The importance of this framework is apparent from a 2017 study that was carried out in the sub county of Chereng'any within the Tranz Nzoia County [21]. Our study concluded that at the local level the county government had not prioritised healthcare. Over $70 \%$ of the health budget was towards the payment of remuneration and personal emoluments for healthcare workers. The remainder of the budget was allocated to finance development of healthcare in the 5 sub counties within Trans Nzoia. We had singled out Chereng'any as the case study and observed that a majority of the dispensaries and health centres lacked sufficient healthcare workers, shortages in drugs supply and lack of adequate medical equipment. The $30 \%$ out of the total health budget prepared by the Tranz Nzoia County was to be shared between its five sub counties. Chereng'any received a lesser allocation.

A fiscal health framework would have guided the Trans Nzoia County in costing for the delivery of healthcare within its sub counties. The fiscal health framework would have guided the development of health programs adequately funded out of the $30 \%$ of the health budget allocated towards development expenditure. It would have also identified different streams of revenue that could be mobilised at county level for health. In so doing, this fiscal health framework, I argue, would redefine the state-society relationship for healthcare delivery. There would raise between government and society a reciprocal fiscal duty towards healthcare financing.

If the Kenyan government is to meet its commitments to health financing by either allocating the $15 \%$ Abuja target or to maintain the WHO recommended 5\% health budget for maternal and child health care, additional domestic revenue must be mobilised. I have shown that the current health expenditure set at $3.9 \%$ of the total 
budget is insufficient when compared to the government's commitment under the Abuja Declaration and the WHO recommendation. While the government has adopted the Kenya Health Policy 2012-2030 identifying 12 health programs to be implemented in time bound stages, it has been estimated that there is a shortfall of Kenya Shillings 242 billion in ensuring their implementation over the 2014-18 fiscal period. Thus, the next section addresses the question on what the government has done towards raising additional domestic revenue. Thereafter, I introduce zakat as a potential revenue stream.

\section{Innovative Health Financing Methods}

Each fiscal year the Kenyan government allocates a health budget. I have shown in the previous sections that this budget has been on a reducing scale. It is currently fixed at 3.9\%. Domestic revenue collected countrywide, donor aid and external borrowings make up the budget each fiscal year. The revenue collected domestically is not sufficient hence reliance is placed on donor aid and external borrowings. The latter two are dependent on external forces not within the control of government. The uncertainty of donor aid and external borrowings reinforce my argument on the need to explore alternative revenue generating strategies locally so that there is less reliance on donors and public debt. I address this section in two parts. First, I consider the government schemes that generate extra revenue locally to finance healthcare. Second, I briefly explain a strategy for increasing domestic spending on health in Kenya. These two considerations shall sum up the argument on increasing domestic spending for health. I now turn to my first consideration.

\section{Schemes That Generate Extra Revenue Locally}

There is no government led innovative intervention that publicly mobilises additional domestic revenue for health in Kenya. For example, a specific tax earmarked for health. In finance, legal rights exist in reality when and if they have budgetary line. If the state claims to grant the right to free health, this will only take place on the ground if there are adequate resources to build clinics near communities. This conceptual lacuna in the human rights principles that stopped short of stating resources were required has impeded national realization of the right to health as it relies solely on political will and the budget allocated to the health sector. In the absence of a fiscal health framework, innovative ways to target additional revenue for health by the government remains an academic exercise.

Innovative health financing strategies in Kenya fall into three groups; public - private partnerships, out of pocket payments and donor led financing of specific health programs. In 2015 the government entered into a public - private partnership scheme with GE Healthcare Africa to provide medical equipment at county level under a seven-year Managed Equipment Services Partnership. Under this partnership the government can budget healthcare expenditure over several years by deferring upfront capital outlay [22]. This means that the government is a debtor to GE Healthcare Africa. This form of public private partnerships does not address the issue of raising additional domestic revenue. Rather, it increases the government's debt. User fees are also imposed for the private sector to recover their capital spent under this scheme.

Out of pocket payments have supported Kenya's healthcare sector. User fees paid at the point of accessing healthcare have partially met the financing needs of dispensaries and health centres in rural areas where government financing has been constrained. Recognising the importance of out of pocket payments the private sector created the M-Tiba health financing scheme. This scheme is managed by Safaricom Limited; a telecommunication service provider together with UAP Insurance in Kenya. Under this scheme, an insurance policyholder would set aside a sum of money in contemplation of future healthcare financing. The amount set aside is stored on their mobile application and is the premium paid to UAP. Depending on the premium paid, UAP then provides healthcare coverage to the policyholder by directly remitting the cost to the service provider that has subscribed to the M-Tiba scheme. While this is an innovative scheme intended to increase access to healthcare, it is dependent on monies an individual is to set aside on a monthly basis. In section 2.3, I pointed out that a majority of the Kenyan population lives below the poverty line, and $38 \%$ of sick people were unable to access healthcare in 2007 because they lacked money. This innovative scheme therefore serves to benefit those with the ability to pay leaving out those who are unable and most vulnerable.

Donor led financing of specific health programs have also developed innovative health financing methods through the use of the voucher program. This voucher program funds maternal healthcare, family planning, and gender violence services in selected rural areas in Kenya. Under the Safe Motherhood Voucher, women are entitled to a variety of services from professional antenatal care, delivery services, and referral to hospitals when needed. However, members of the target group have to pay Kenya Shillings 200 for a safe motherhood voucher. The Family Planning Voucher entitles clients to long term contraception methods including monitoring, referral and consultation. This voucher offers a range of family planning procedures such as intrauterine contraceptive devices (IUCD) and both male (vasectomy) and female (bilateral tubal ligation) voluntary contraceptive surgery. The voucher costs Kenya Shillings 100 and buys up to Kshs 3,000 worth of services. The Gender Violence Services Voucher entitles victims to medical and surgical treatment as well as counselling. It is provided to clients free of charge. Those with the ability to pay are able to access the healthcare services provided under the two former vouchers.

Discussions on innovations at the international level include suggestions of new taxes and funds. However, they do not canvass the loss of uncollected revenues through tax evasion and aggressive tax avoidance; the use of current funds like carbon tax which is collected on global emissions but deposited in one state to be used at will or tobacco tax collected domestically but not earmarked to health-related spending. The emphasis is on new ideas such as the Health Impact Fund [23], instead of fixing the existing ones. The new ideas are not widespread probably due to the novel nature of the idea and possibly due to challenges involved in adding a new mechanism to the already burdened international system. Existing 
ideas such as earmarking transaction taxes, the tobacco tax and part of the climate fund to cater for health needs are interesting. But, they are not fleshed out in terms of guiding principles and an overall structure within which these taxes are to operate to finance health domestically.

The existing ideas are also dependent on the socio-economic development of a country. Half of the Kenyan population lives under the poverty line therefore, tax mobilisation is not the best option to finance health. To increase health financing reliance should not be placed on collecting more taxes by tighter controls on evasion schemes, or earmarking part of the climate fund. Kenya has a growing debt that needs repayment. Tapping into the uncollected taxes through efficient collection mechanisms should be aimed to reduce the debt. Kenya's climate fund also requires an additional US\$1 billion to operationalize. Despite the proposals for innovative health financing strategies, studies have shown that there has been a lack of proper monitoring of health finance at the institutional level. This has resulted in low health spending as a result of corruption, and bureaucracy in the timely release of funds. While new financing methods may be useful it may likely add on more complication to an already complex system.

\section{Strategy for Increasing Domestic Spending on Health in Kenya}

In section 2.3, I showed that the health budget for the 2015/16 and $2016 / 17$ fiscal years were at $4.1 \%$ of the total budget. I also showed that health spending during these years stretched the budget to $18.97 \%$ and $19.16 \%$ respectively. This means that government spent more on health in these years than it had allocated to the health sector. I argue that even if corruption resulted in lower health spending, the corruption targeted the $4.1 \%$ of the budget allocated. If transparency and accountability resulted in optimal use of the $4.1 \%$ health budget, there would still be a deficit to be balanced through donor aid, out of pocket payments and external borrowing. The Kenyan health sector is underfunded. This justifies the need to increase domestic spending on public health.

In the introduction of this paper, I asked two questions. First, whether there is a need to increase domestic spending on public health. Second, whether an increase in public health spending will result in improving access and availability of public health. I answered these two questions in the affirmative under the previous two sections. I also explained that reliance on donor aid and external borrowings to fund healthcare in the long run is not sustainable. A fiscal health framework to supplement the health budget and to plan the financing of the health programs under the Kenya Health Policy 2012-2030 is significant. A fiscal health framework provides the fiscal space to broaden revenue generating streams in sourcing for additional funds. I seek to contribute towards broadening Kenya's fiscal space for health financing. I recommend the inclusion of zakat as a domestic health financing strategy. The potential of zakat as a strategy however, is subject to further research.

Zakat in Kenya is not regulated by the government. There is no legal framework for its governance. There are no documented records and readily available data that shows how much zakat is annually collected, by whom and the purpose for which the revenue is utilized. There are few formal organisations and small informal self-organized groups that collect zakat. These organisations then provide a plan on how the total zakat collected is to be distributed. This information is normally limited to the members of these groups. For zakat to be placed within the fiscal space in Kenya it has to fulfill four conditions. First, there must be theological clarity on the use of Islamic fiscal law to support health financing. Second, there must be legal validity justifying a plural state to rely on religious funds. Third, the use of zakat must not discriminate in favour of Muslims. Finally, the administration and governance of zakat must be legally acceptable under Kenyan and Islamic laws [24-39].

\section{Conclusion}

In this paper I set out to establish whether the Kenyan health sector was sufficiently financed. My findings revealed that the health sector faces funding challenges. Financial constraints were also present during colonial rule. After Independence, a number of health programs were identified under different policies targeted towards the provision of available and accessible healthcare. However, the problem of limited financing impeded their implementation. The concept of African Socialism under Sessional Paper No. 10 of 1965 did recognise the importance of healthcare, but relegated it in favour of growth. The budget allocated to the health sector further shows that little attention has been paid to health financing over the years. Instead, out of pocket payments and donor aid have helped sustain the health sector. Neither has the government met the $15 \%$ Abuja target or the 5\% WHO recommended allocation for maternal and child health coverage. The Kenyan government has consistently kept its health budget below 5\% since 2013. Despite identifying 12 health programs under the recent Kenya Health Policy 2012-2030, a health financing strategy also remains lacking. Kenya is spending more on healthcare than the government is budgeting for. This increase is met through external borrowings, donor aid and out of pocket payments which in the long run are not sustainable. I then argued that the lack of a fiscal health framework has resulted in limited domestic spending on public health. There is clearly a need to increase domestic health spending. It then follows that government should meet the increment either by mobilising additional revenue or identifying potential revenue sources. I argued that there is room within Kenya's fiscal space to source for additional revenue that is already locally available. I recommend the inclusion of zakat as a revenue source for health financing. The legal validity and theological justification under Islamic law of this recommendation however, is to be subjected to further research.

\section{References}

1. Ann Beck (1970) A History of the British Medical Administration of East Africa, 1900-1950. Cambridge, Massachusetts.

2. Adolf Wagner (1890) Finanzwissenschaft, Leipzig.

3. David W Throup (1990) Economic and Social Origins of Mau Mau 19451953. Ohio University Press, USA.

4. Di McIntyre, Filip Meheus, John Arne Rottingen (2017) What level of domestic government health expenditure should we aspire to for universal health coverage? Health Economics, Policy and Law 12(2): 125-137. 
5. Frank Furedi (1989) The Mau Mau War in Perspective London: James Currey 61(3): 251.

6. Frederick Cooper (1988) Mau Mau and the Discourses of Decolonisation. Journal of African History 29(2): 313-320.

7. George Ndege (2001) Health, State and Society in Kenya: Faces of Contact and Change. USA: University of Rochester Press, USA.

8. (2018) GIZ, Vouchers: making motherhood safer for Kenya's poorest women.

9. The Second National Health Sector Strategic Plan of Kenya 2005-2010. Government of Kenya, Ministry of Health.

10. The First National Health Sector Strategic Plan of Kenya 1994-2004. Government of Kenya, Ministry of Health.

11. (1994) Kenya's Health Policy Framework. Government of Kenya, Ministry of Health.

12. HWO Okoth Ogendo (1972) The Politics of Constitutional Change in Kenya since Independence 1963-69. African Affairs, 71(282): 9-34.

13. John Iliffe (1998) East African Doctors: A history of the modern profession. Cambridge University Press 94(2): 229-230.

14. John Lonsdale (1990) Mau Maus of the Mind: Making Mau Mau and Remaking Kenya. Journal of African History 31(3): 393-421.

15. Joseph Schumpeter (1918) The crisis of the state.

16. (2010) Sectoral perspectives on corruption in Kenya: The case of the public health care delivery. Kenya Anti Corruption Commission.

17. Latif LA, Simiyu F, Waris A (2017) A Case Study on the Application of Human Rights Principles in Health Policy Making and Porgramming in Chereng any Sub County in Kenya. Integr J Glob Health 1:1.

18. Leah Kimathi (2017) Challenges of the devolved health sector in Kenya: Teething problems or systemic contradictions? Africa Development 42(1): 55-77.

19. Marshall Clough (1998) Mau Mau Memoirs: History, Memory and Politics.

20. Tunis (2012) Ministerial Conference on Value for Money, Sustainability and Accountability in the Health Sector.

21. (2014) Kenya Health Policy 2014-2030: Towards Attaining the Highest Standards of Health. Ministry of Health.

22. Health sector strategic and investment plan 2013-2017: Transforming health: Accelerating attainment of health goals. Ministry of Health.
23. (2009) Ministry of Public Health and Sanitation \& Ministry of Medical Services.

24. Miriam S, Chaiken (1998) Primary Health Care Initiatives in Colonial Kenya. World Development 26(9): 1701-1717.

25. (2012) National Hospital Insurance Fund Act, Chapter 255 of the Laws of Kenya.

26. Perales N, A Dutta, T Maina (2015) Resource Needs for the Kenya Health Sector Strategic and Investment Plan: Analysis Using the OneHealth Tool. Washington DC, USA.

27. (2008)'Adoption of the ouagadougou declaration on primary health care and health systems in Africa: achieving better health for Africa in the new millennium. World Health Organization, Regional Committee for Africa.

28. (1983) Republic of Kenya. District Focus rural development.

29. Republic of Kenya. Development Plans, 1966-1978.

30. Robert M Maxon (1993) Struggle for Kenya: The Loss and Reassertion of Imperial Initiative1912-1923. Associated University Presses, London.

31. (1965) Sessional Paper No. 10 of 1965: African Socialism and Its Application to Planning in Kenya.

32. Alfred Milner (1923) Questions of the Hour London.

33. Tabitha Kanogo (1987) Squatters and the Roots of Mau Mau 1905-1963 Ohio University Press.

34. (2006) The Addis Ababa Declaration on Community Health in the African Region.

35. (2014) Briefing, Climate change financing in Kenya. The International Institute for Environment and Development (IIED)

36. (2011)The Kenya health sector integrity study report. Transparency International Kenya.

37. (2001) African summit on HIV/AIDS, tuberculosis and other related infectious diseases: Abuja declaration on HIV/AIDS, tuberculosis, and other infectious diseases. New York, USA.

38. WE Gladstone (1981) The Past and Present Administrations', quoted from Richard Kesner, Economic Control and Colonial Development: Crown Colony Financial Management in the age of Joseph Chamberlain.

39. Yash P Ghai, JPWB McAuslan, Patrick McAuslan (1970) Public law and political change in Kenya: A study of the legal framework of government from colonial times to the present. Oxford University Press 28(536).

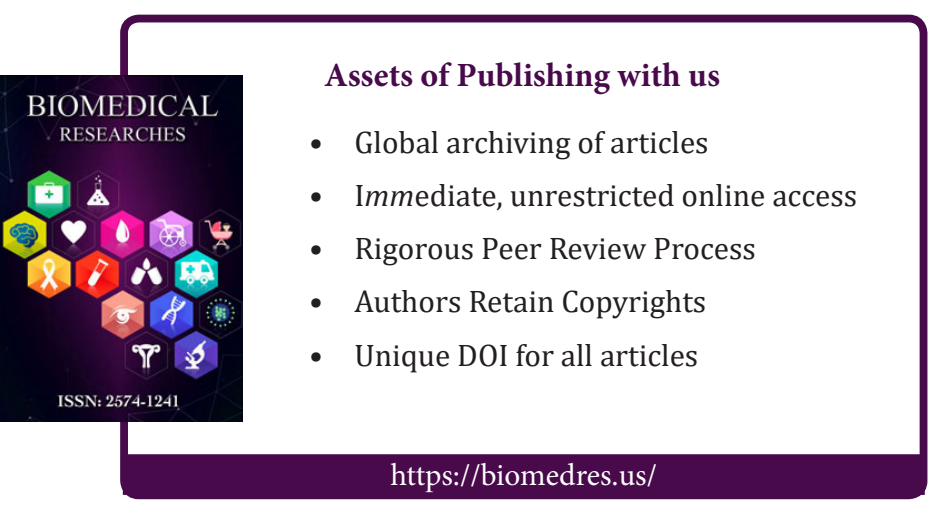

